\title{
Polyaniline-copper composite: a non-precious metal cathode catalyst for low-temperature fuel cells
}

Jayesh M. Sonawane*1, 2, 3,4, Deepak Pant ${ }^{6}$, Prakash C. Ghosh*1,2, Samuel B. Adeloju*1,3,5

${ }^{1}$ IITB-Monash Research Academy,

Indian Institute of Technology Bombay,

Mumbai, 400076, India.

${ }^{2}$ Department of Energy Science and Engineering,

Indian Institute of Technology Bombay,

Mumbai-400076, India.

${ }^{3}$ School of Chemistry,

Monash University,

Clayton Campus, Victoria 3800,

Australia.

${ }^{4}$ Department of Chemical Engineering and Applied Chemistry,

University of Toronto, Toronto,

ON, M5S 3E5, Canada

${ }^{5}$ Faculty of Science,

Charles Sturt University,

Albury, New South Wales 2640, Australia

6Separation and Conversion Technology,

Flemish Institute for Technological Research (VITO),

Boeretang 200, 2400 Mol, Belgium.

* Corresponding authors

jay1iisc@gmail.com; jayesh.sonawane@mail.utoronto.ca; Tel.: +1 6477642158

sadeloju@csu.edu.au; Tel.: +61260519681

chhamugram@gmail.com; pcghosh@iitb.ac.in; Tel.: +91 22 2576-7896 


\section{CP/PANi-Cu}
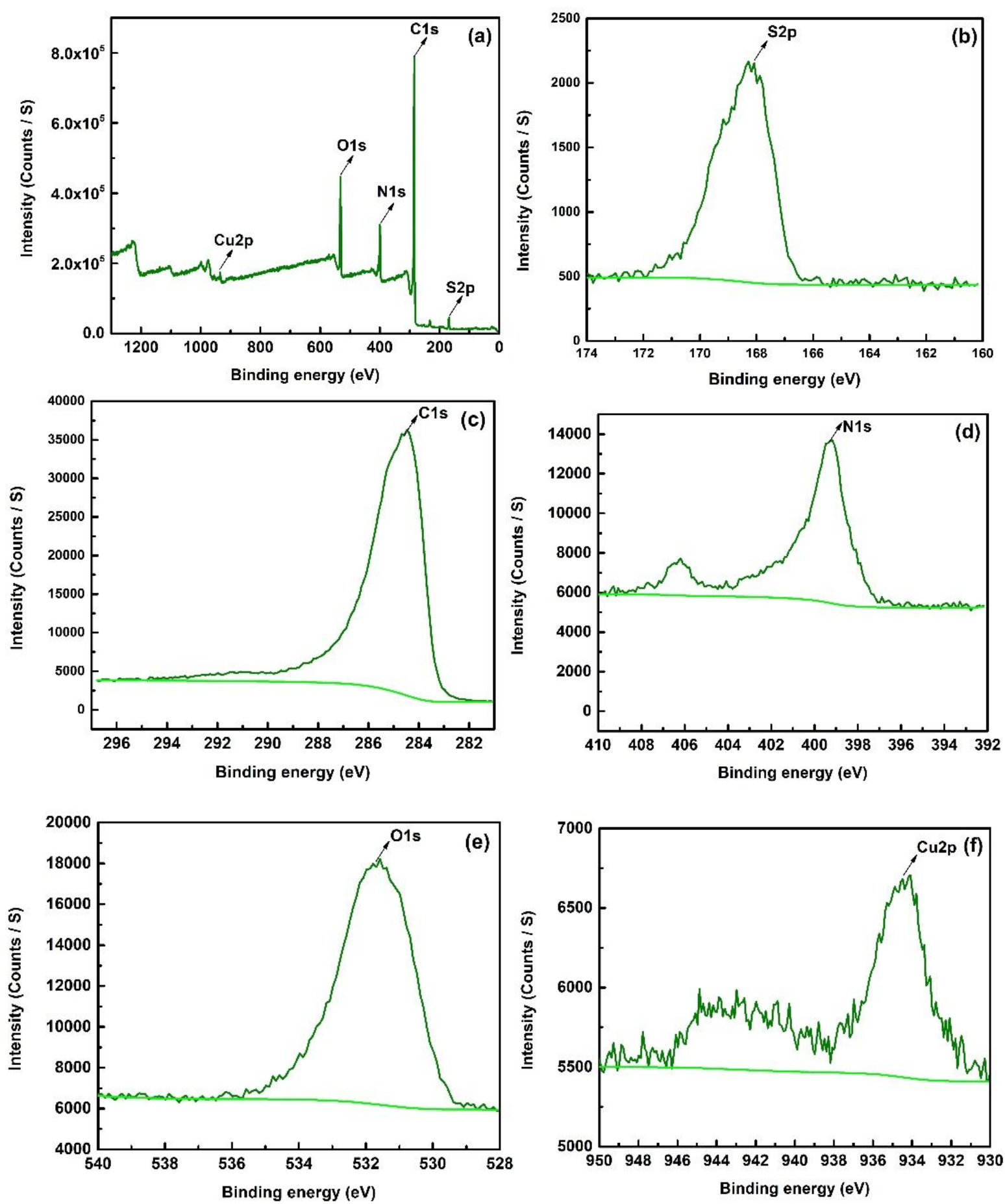

Figure S1 Elemental composition of $\mathrm{CP} / \mathrm{PANi}-\mathrm{Cu}$ a) general survey of elements b) S2p c) C1s d) N1s e) O1s and f) Cu2p 

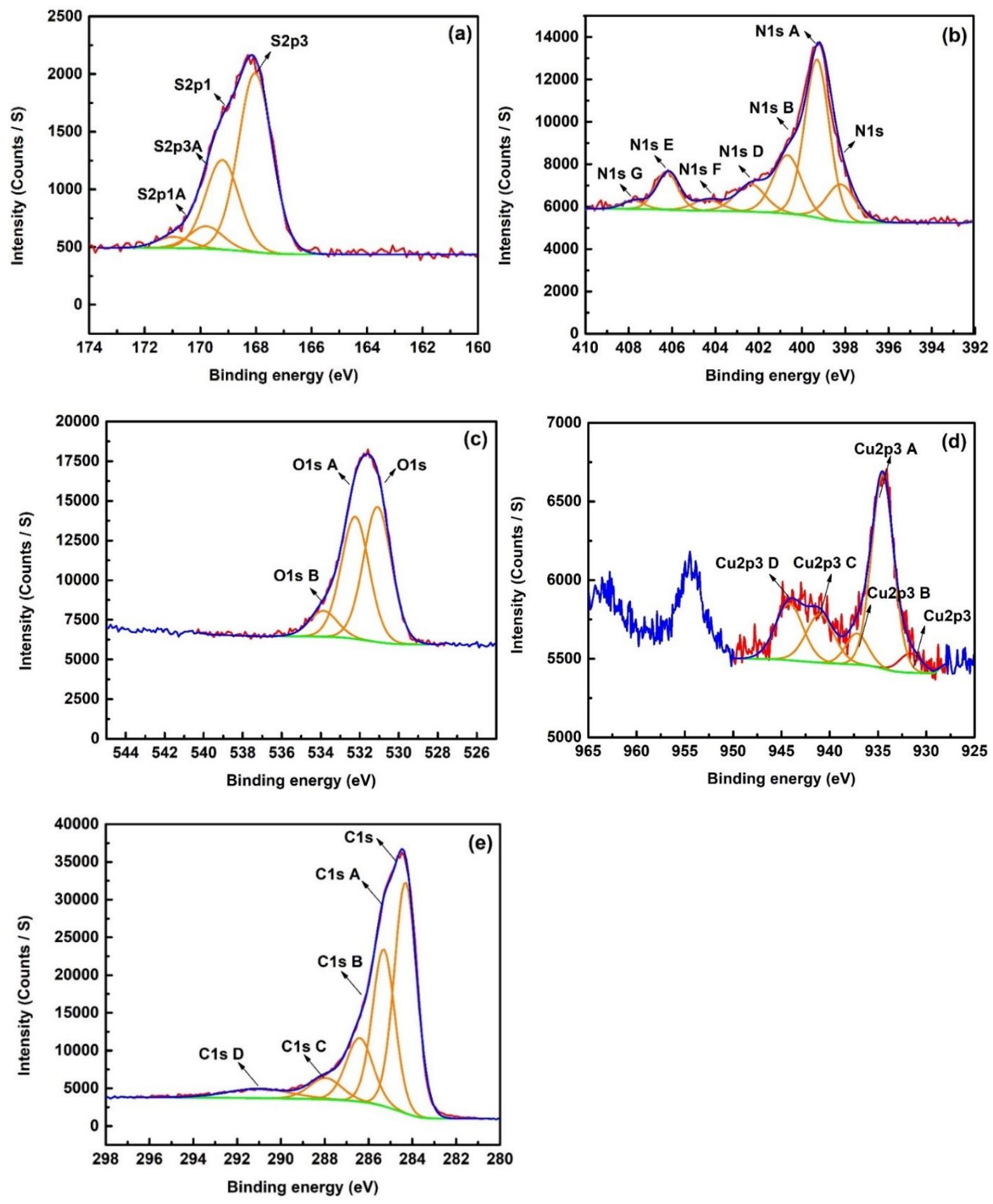

Elemental states and composition of $\mathrm{CP} / \mathrm{PANi}-\mathrm{Cu}$ a) sulfur) carbon d) nitrogen e) oxygen and f) copper (Figure S2) 
STable 1 Elemental ID and quantification from general survey

\begin{tabular}{cccccc}
\hline Name & Peak BE & FWHM eV & Atomic $\%$ & Q & SF ALTHERMO1 \\
\hline S2p & 168.28 & 2.39 & 1.70 & 1 & 1.881 \\
\hline C1s & 284.63 & 2.20 & 73.56 & 1 & 1.000 \\
\hline N1s & 399.30 & 1.77 & 12.93 & 1 & 1.676 \\
\hline O1s & 531.63 & 2.48 & 11.28 & 1 & 2.881 \\
\hline Cu2p3 & 934.49 & 2.73 & 0.52 & 1 & 18.147 \\
\hline
\end{tabular}

STable 1.1 Elemental ID and quantification of various states of sulfur

\begin{tabular}{lrrrrr}
\hline Name & Peak BE & FWHM eV & Atomic \% & Q & SF ALTHERMO1 \\
\hline S2p3 & 168.03 & 1.42 & 88.83 & 1 & 1.245 \\
\hline S2p1 & 169.21 & 1.42 & 0.00 & 0 & 0.636 \\
\hline S2p3 A & 169.78 & 1.42 & 11.17 & 1 & 1.245 \\
\hline S2p1 A & 170.96 & 1.42 & 0.00 & 0 & 0.636 \\
\hline
\end{tabular}

STable 1.2 Elemental ID and quantification of various states of nitrogen

\begin{tabular}{lrrrrr}
\hline Name & Peak BE & FWHM eV & Atomic \% & Q & SF ALTHERMO1 \\
\hline N1s & 398.22 & 1.54 & 11.93 & 1 & 1.676 \\
\hline N1s A & 399.31 & 1.34 & 44.20 & 1 & 1.676 \\
\hline N1s B & 400.67 & 1.54 & 18.82 & 1 & 1.676 \\
\hline N1s D & 402.39 & 1.64 & 9.46 & 1 & 1.676 \\
\hline N1s E & 406.26 & 1.22 & 9.77 & 1 & 1.676 \\
\hline N1s F & 404.39 & 1.54 & 3.60 & 1 & 1.676 \\
\hline N1s G & 407.83 & 1.22 & 2.22 & 1 & 1.676 \\
\hline
\end{tabular}

STable 1.3 Elemental ID and quantification of various states of oxygen

\begin{tabular}{lrrrrr} 
Name & Peak BE & FWHM eV & Atomic \% & Q & SF ALTHERMO1 \\
\hline O1s & 531.09 & 1.69 & 47.69 & 1 & 2.881 \\
\hline O1s A & 532.23 & 1.69 & 43.16 & 1 & 2.881 \\
\hline O1s B & 533.86 & 1.69 & 9.14 & 1 & 2.881 \\
\hline
\end{tabular}

STable 1.4 Elemental ID and quantification of various states of copper

\begin{tabular}{lrrrrr}
\hline Name & Peak BE & FWHM eV & Atomic \% & Q & SF ALTHERMO1 \\
\hline Cu2p3 & 931.65 & 2.68 & 5.11 & 1 & 18.147 \\
\hline Cu2p3 A & 934.52 & 2.68 & 51.31 & 1 & 18.147 \\
\hline Cu2p3 B & 937.18 & 2.68 & 8.30 & 1 & 18.147 \\
\hline Cu2p3 C & 940.99 & 3.37 & 16.26 & 1 & 18.147 \\
\hline Cu2p3 D & 944.19 & 3.37 & 19.03 & 1 & 18.147 \\
\hline
\end{tabular}

STable 1.5 Elemental ID and quantification of various states of carbon

\begin{tabular}{rrrrrr}
\hline Name & Peak BE & FWHM eV & Atomic \% & Q & SF ALTHERMO1 \\
\hline C1s & 284.32 & 1.20 & 44.28 & 1 & 1.000 \\
\hline C1s A & 285.31 & 1.20 & 30.09 & 1 & 1.000 \\
\hline C1s B & 286.41 & 1.44 & 14.66 & 1 & 1.000 \\
\hline C1s C & 287.96 & 1.73 & 5.92 & 1 & 1.000 \\
\hline C1s D & 290.98 & 3.37 & 5.05 & 1 & 1.000 \\
\hline
\end{tabular}




\section{$\mathbf{C P} / \mathbf{P t}$}
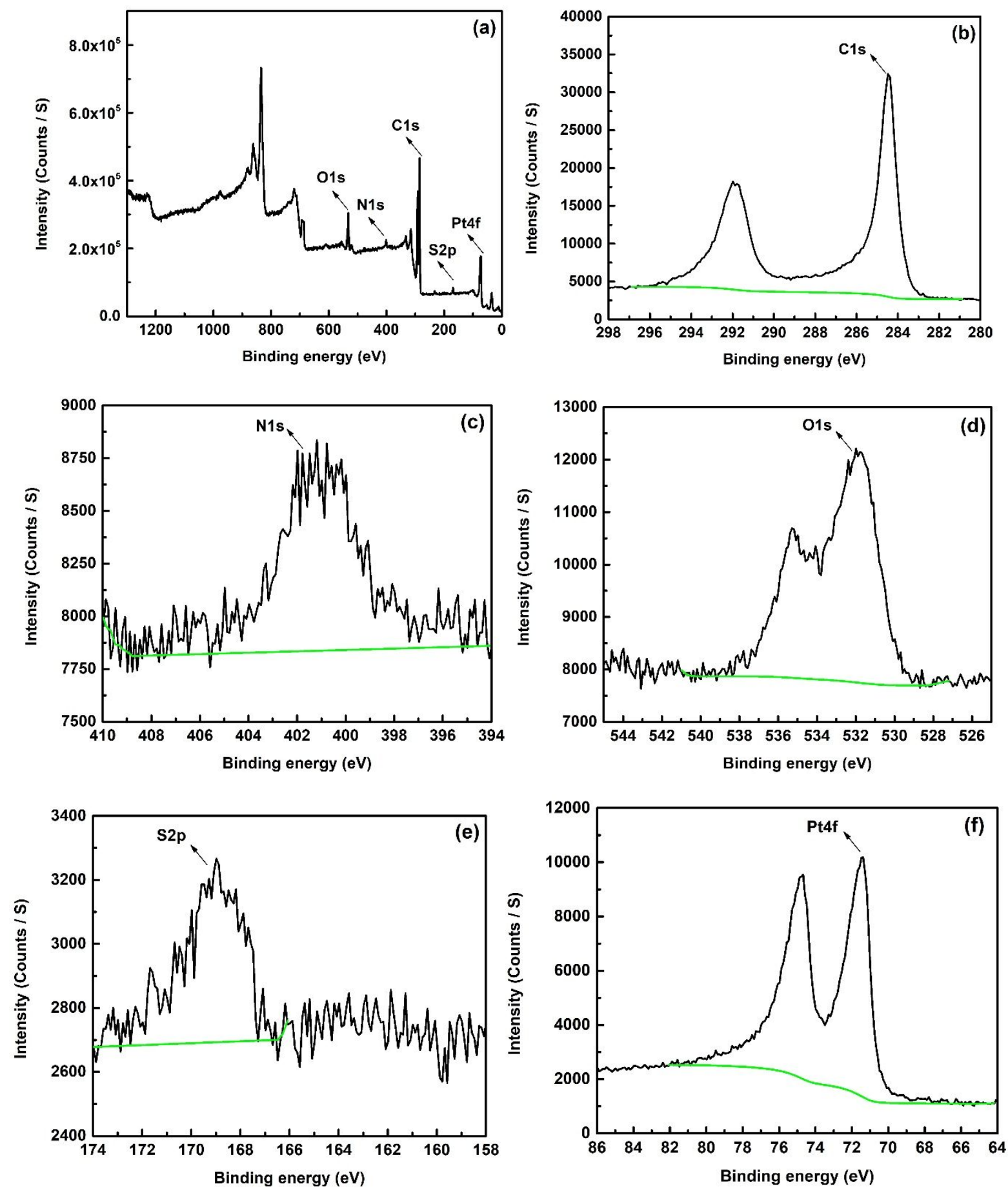

Figure S3 Elemental composition of $\mathrm{CP} / \mathrm{Pt}$ a) general survey of elements b) C1s c) N1s d) O1s e) S2p and f) Pt $4 f$ 
STable 2 Elemental ID and quantification from general survey

\begin{tabular}{lrrrrr}
\hline Name & Peak BE & FWHM eV & Atomic \% & Q & SF \\
\hline C1s & 284.47 & 0.97 & 91.21 & 1 & 1.000 \\
\hline N1s & 400.97 & 2.52 & 1.70 & 1 & 1.676 \\
\hline O1s & 531.95 & 2.94 & 5.07 & 1 & 2.881 \\
\hline S2p & 168.96 & 2.38 & 0.87 & 1 & 1.881 \\
\hline Pt4f & 71.54 & 1.63 & 1.16 & 1 & 16.678 \\
\hline
\end{tabular}

STable 2.1 Elemental ID and quantification of various states of carbon

\begin{tabular}{lrrrrr} 
Name & Peak BE & FWHM eV & Atomic \% & Q & SF \\
\hline C1s & 284.46 & 0.91 & 36.45 & 1 & 1.000 \\
\hline C1s A & 285.38 & 0.91 & 6.42 & 1 & 1.000 \\
\hline C1s B & 286.28 & 1.44 & 7.44 & 1 & 1.000 \\
\hline C1s C & 287.93 & 1.92 & 5.75 & 1 & 1.000 \\
\hline C1s D & 289.79 & 1.67 & 3.94 & 1 & 1.000 \\
\hline C1s E & 291.90 & 1.59 & 31.48 & 1 & 1.000 \\
\hline C1s F & 293.68 & 1.80 & 6.50 & 1 & 1.000 \\
\hline C1s G & 283.46 & 0.91 & 2.02 & 1 & 1.000 \\
\hline
\end{tabular}

STable 2.2 Elemental ID and quantification of various states of nitrogen

\begin{tabular}{lrrrrr}
\hline Name & Peak BE & FWHM eV & Atomic \% & Q & SF \\
\hline N1s & 398.20 & 1.64 & 11.94 & 1 & 1.676 \\
\hline N1s A & 401.90 & 1.64 & 36.00 & 1 & 1.676 \\
\hline N1s B & 400.28 & 1.64 & 37.85 & 1 & 1.676 \\
\hline N1s D & 404.20 & 2.40 & 14.20 & 1 & 1.676 \\
\hline
\end{tabular}

STable 2.3 Elemental ID and quantification of various states of oxygen

\begin{tabular}{lrrrrr}
\hline Name & Peak BE & FWHM eV & Atomic \% & Q & SF \\
\hline O1s & 531.67 & 1.32 & 28.79 & 1 & 2.881 \\
\hline O1s A & 532.78 & 1.32 & 21.17 & 1 & 2.881 \\
\hline O1s B & 534.06 & 1.32 & 14.31 & 1 & 2.881 \\
\hline O1s C & 535.33 & 1.32 & 19.36 & 1 & 2.881 \\
\hline O1s D & 536.67 & 1.32 & 6.12 & 1 & 2.881 \\
\hline O1s E & 530.62 & 1.32 & 10.25 & 1 & 2.881 \\
\hline
\end{tabular}

STable 2.4 Elemental ID and quantification of various states of oxygen

\begin{tabular}{lrrrrr}
\hline Name & Peak BE & FWHM eV & Atomic \% & Q & SF \\
\hline S2p3 & 168.57 & 1.97 & 82.56 & 1 & 1.245 \\
\hline S2p1 & 169.75 & 1.97 & 0.00 & 0 & 0.636 \\
\hline S2p3 A & 171.30 & 1.97 & 17.44 & 1 & 1.245 \\
\hline S2p1 A & 172.48 & 1.97 & 0.00 & 0 & 0.636 \\
\hline
\end{tabular}

STable 2.5 Elemental ID and quantification of various states of platinum

\begin{tabular}{lrrrrr}
\hline Name & Peak BE & FWHM eV & Atomic \% & Q & SF \\
\hline Pt4f7 & 71.43 & 1.49 & 100.00 & 1 & 9.327 \\
\hline Pt4f5 & 74.76 & 1.49 & 0.00 & 0 & 7.350 \\
\hline
\end{tabular}



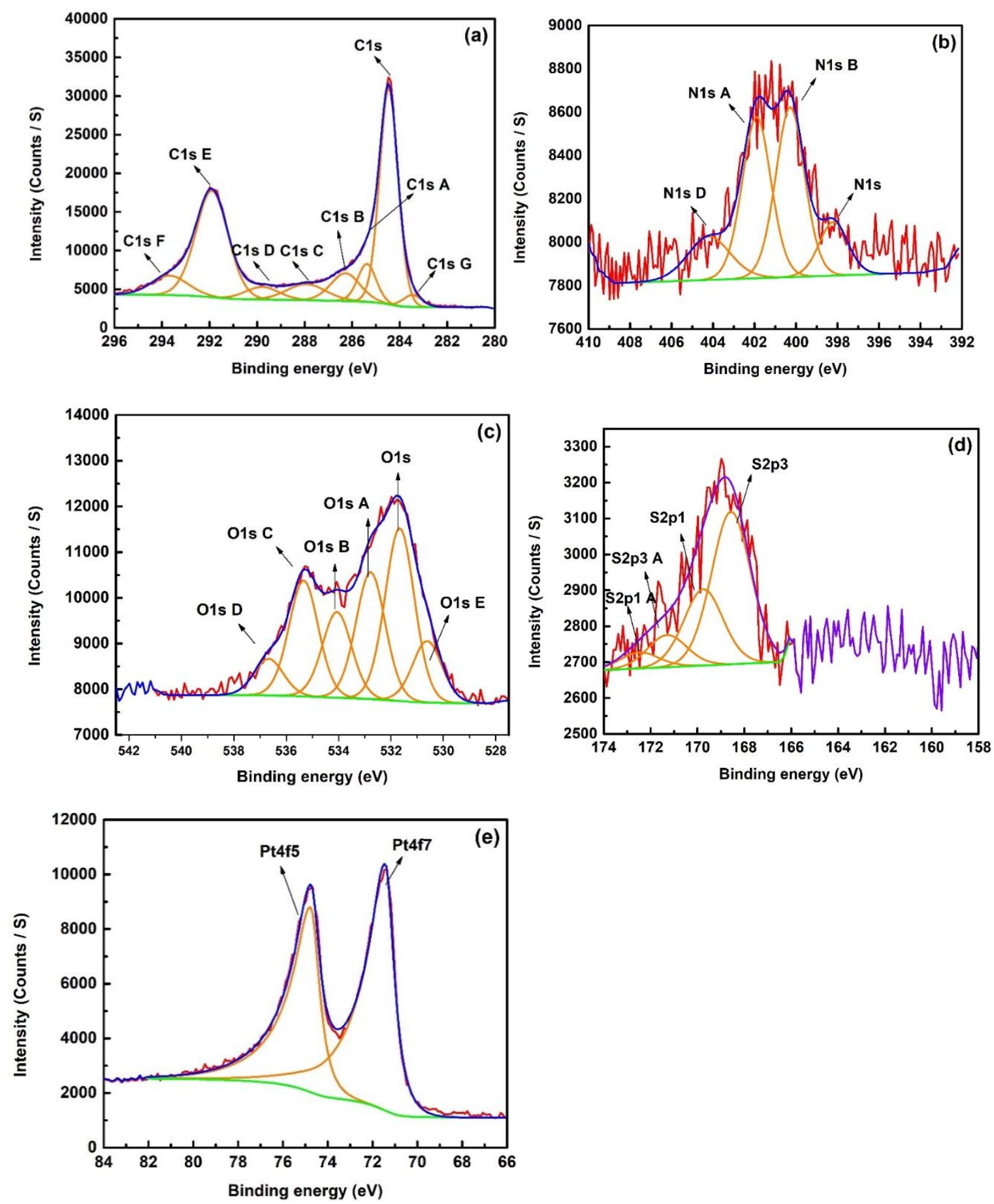

Figure S4 Elemental states and composition of $\mathrm{CP} / \mathrm{Pt}$ a) carbon b) nitrogen c) oxygen d) sulfur and e) platinum (Used an asymmetric peak which is appropriate for Pt metal 
Stable 3 Exchange current density $\left(j_{0}\right)$ and charge transfer resistance $\left(R_{c t}\right)$ of $\mathrm{CP} / \mathrm{Pt}$ and $\mathrm{CP} / \mathrm{PANi}-\mathrm{Cu}$

\begin{tabular}{|c|c|c|c|c|c|}
\hline $\begin{array}{l}\text { CP/Pt } \\
\text { Catalyst } \\
\text { loading } \\
\left.(\mathbf{m g ~ c m})^{-2}\right)\end{array}$ & $\begin{array}{l}\mathbf{j}_{0} \mathbf{m A} / \\
\mathbf{c m}^{-2}\end{array}$ & $\begin{array}{l}R_{c t} / \Omega \\
\mathbf{c m}^{-2}\end{array}$ & $\begin{array}{l}\text { CP/PANi-Cu } \\
\text { Polymerisation and } \\
\text { catalyst deposition } \\
\text { time (min) }\end{array}$ & $\begin{array}{l}\boldsymbol{j}_{0} \mathbf{m A} / \\
\mathbf{c m}^{-2}\end{array}$ & $\begin{array}{l}R_{c t} / \Omega \\
\mathrm{cm}^{-2}\end{array}$ \\
\hline 00 (pristine) & 0.00347 & 36.983 & 00 (pristine) & 0.00347 & 36.983 \\
\hline 25 & 0.01041 & 12.328 & 05 & 0.00808 & 15.882 \\
\hline 05 & 0.03246 & 3.953 & 10 & 0.03521 & 3.645 \\
\hline 75 & 0.05883 & 2.181 & 15 & 0.03866 & 3.319 \\
\hline 1.0 & 0.06837 & 1.877 & 20 & 0.05268 & 2.436 \\
\hline 1.25 & 0.07968 & 1.611 & 25 & 0.08816 & 1.456 \\
\hline 1.50 & 0.0864 & 1.485 & 30 & 0.07334 & 1.75 \\
\hline
\end{tabular}

\section{FTIR of CP/Pt composite}

The FTIR spectra obtained for the CP/Pt composite is shown in Fig S4a. Evidently, the presence of the carbonyl acid $\mathrm{C}=\mathrm{O}$ stretch and the $\mathrm{N}-\mathrm{H}$ deformation were observed at 1695 and $1549 \mathrm{~cm}^{-1}$, respectively.

The peaks at 1148 and $1210 \mathrm{~cm}-1$ resemble the asymmetric and symmetric vibration of $-\mathrm{CF} 2$ groups in the hydrophobic fluorocarbon backbone. The sulfonate group associated with the Nafion solution expressed symmetric stretching rose at $1059 \mathrm{~cm}^{-1}$. A double peak appeared at $972 \mathrm{~cm}-1$ attributed due to the presence of two ether linkages in the Nafion solution (PTFE) chain. [1]. The peaks at $846 \mathrm{~cm}^{-1}$ and $702 \mathrm{~cm}^{-1}$ were associated with the $\mathrm{SO}_{3}{ }^{-}$group from the Nafion solution [2].
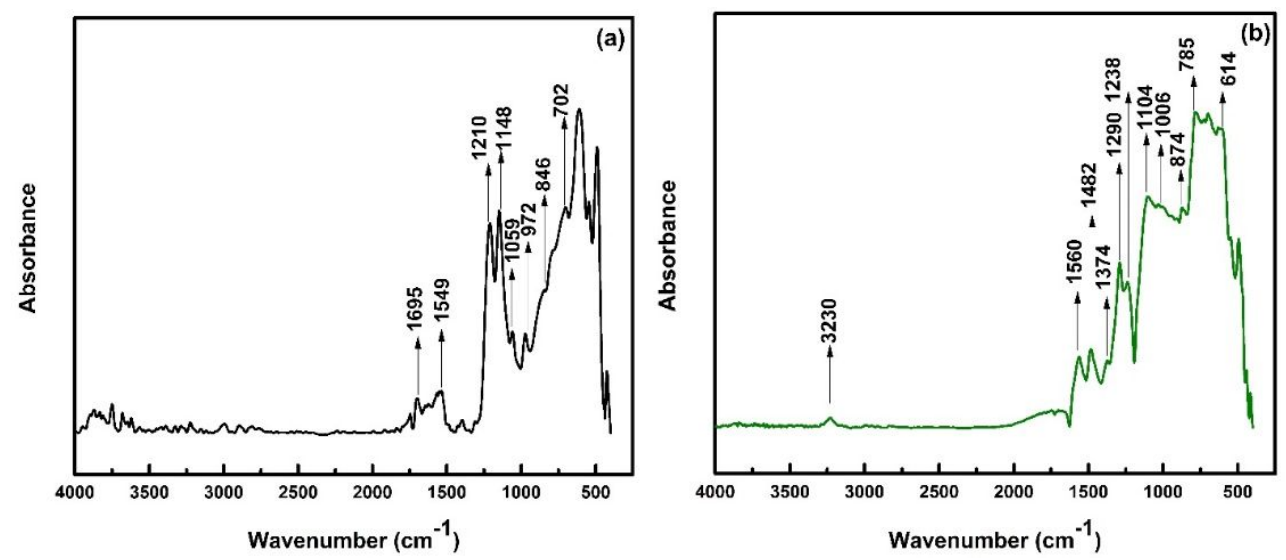
Figure S5. Fourier transform infrared (FTIR) spectra of (a) CP/Pt cathode with $0.5 \mathrm{Pt}$ loading on carbon paper and (b) CP/PANi-Cu cathode electrodeposited for $20 \mathrm{~min}$.

\section{FTIR of CP/PANi-Cu composite}

The FTIR spectra obtained for the $\mathrm{CP} / \mathrm{PANi}-\mathrm{Cu}$ composite in Fig S4b revealed prominent characteristic peaks of a secondary amine $(\mathrm{N}-\mathrm{H})$ at $3230 \mathrm{~cm}^{-1}[3]$, and the $\mathrm{C}=\mathrm{C}$ stretching deformation of the quinoid at 1560 and $1374 \mathrm{~cm}^{-1}$. The peak observed at $1482 \mathrm{~cm}^{-1}$ is attributed to a benzenoid ring system in PANi [4], while the peaks at $1289 \mathrm{~cm}^{-1}$ and $1238 \mathrm{~cm}^{-1}$ were due to the $\mathrm{C}-\mathrm{N}$ stretching of the secondary aromatic amine and the $\mathrm{C}-\mathrm{H}$ bending of the benzenoid, respectively. In addition, the absorption peak at $1104 \mathrm{~cm}^{-1}$ was due to the $\mathrm{N}=\mathrm{Q}=\mathrm{N}$. All of the identified peaks are characteristics and indicative of the presence of the emeraldine form of PANi. The peaks at $614 \mathrm{~cm}^{-1}$ were assigned to the symmetric and antisymmetric stretching of the sulfonate groups [1]. The small peak at $1006 \mathrm{~cm}^{-1}$ was due to the presence of the sulphonic group from the Nafion solution [2]. The presence of the out-of-plane bends of $\mathrm{C}-\mathrm{H}$ on substituted aromatic rings was observed at $874 \mathrm{~cm}^{-1}$. Evidently, the FTIR measurements revealed distinct differences between the $\mathrm{CP} / \mathrm{Pt}$ and $\mathrm{CP} / \mathrm{PANi}-\mathrm{Cu}$ composites based on the identification of the principal functional groups.

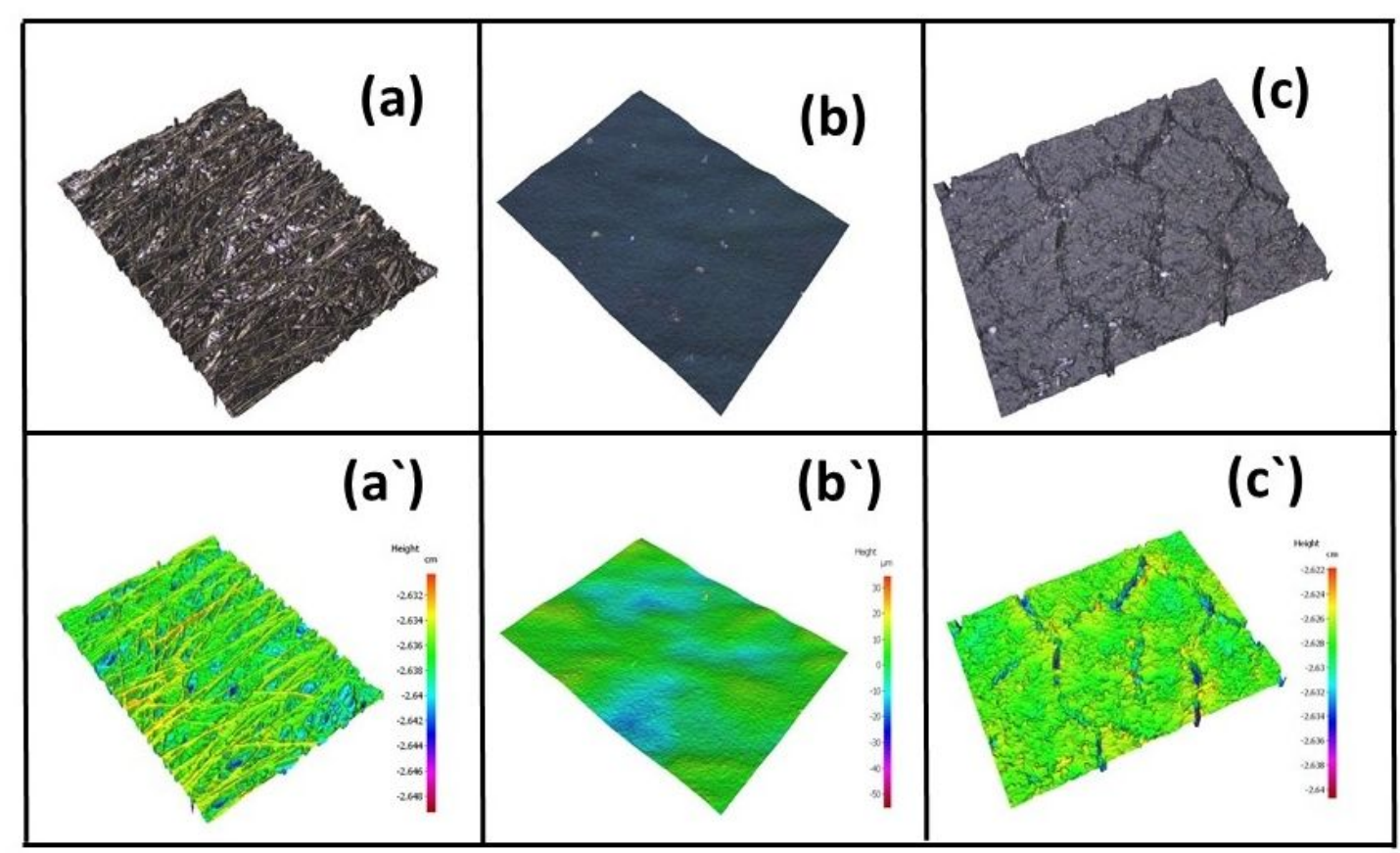

Figure S6. 3D profilometry of (a) pristine carbon paper, (b) carbon paper coated with $0.5 \mathrm{mg}$ $\mathrm{cm}^{-2} \mathrm{Pt}$ as $\mathrm{CP} / \mathrm{Pt} / \mathrm{C}$, and (c) $\mathrm{CP} / \mathrm{PANi}-\mathrm{Cu}$. Electropolymerization time for $\mathrm{CP} / \mathrm{PANi}-\mathrm{Cu}$ coating was 20 mins. 


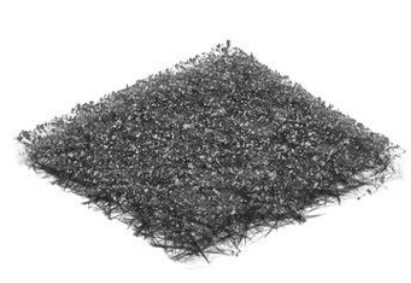

Pt cathode $\left(0.5 \mathrm{mg} \mathrm{cm}^{-2}\right)$
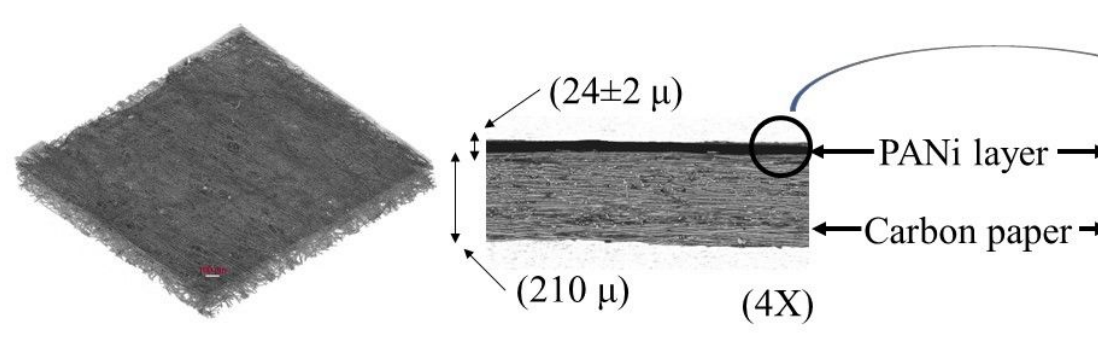

$(4 \mathrm{X})$

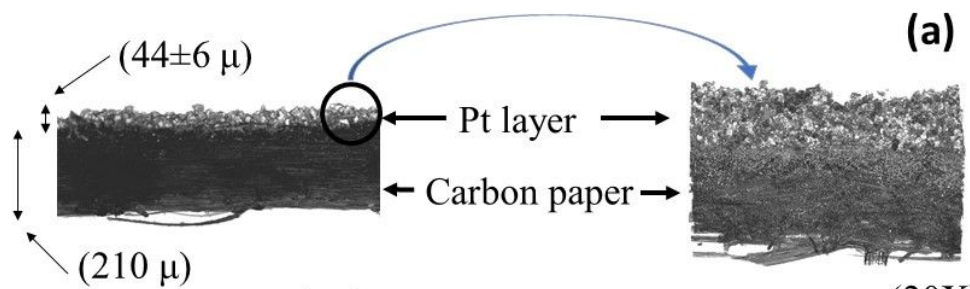

$(20 \mathrm{X})$

PANi cathode (20 min)

Figure S7. 4D X-ray microscopy of (a) CP/Pt with $0.5 \mathrm{mg} \mathrm{cm}^{-2} \mathrm{Pt}$ and (b) $\mathrm{CP} / \mathrm{PANi}-\mathrm{Cu}$ composite. Electropolymerization time for $\mathrm{CP} / \mathrm{PANi}-\mathrm{Cu}$ coating was 20 mins.

\section{References}

1. Zhou, M.; Li, W.; Gu, T. tian; Wang, K.; Cheng, S.; Jiang, K. A sulfonated polyaniline with high density and high rate Na-storage performances as a flexible organic cathode for sodium ion batteries. Chem. Commun. 2015, 51, 14354-14356.

2. Nibel, O.; Schmidt, T.J.; Gubler, L. Bifunctional Ion-Conducting Polymer Electrolyte for the Vanadium Redox Flow Battery with High Selectivity. J. Electrochem. Soc. 2016, 163, A2563-A2570.

3. Beshkar, F.; Zinatloo-Ajabshir, S.; Bagheri, S.; Salavati-Niasari, M. Novel preparation of highly photocatalytically active copper chromite nanostructured material via a simple hydrothermal route. PLoS One 2017, 12, e0158549.

4. Khan, R.; Khare, P.; Baruah, B.P.; Hazarika, A.K.; Dey, N.C. Spectroscopic, Kinetic Studies of Polyaniline-Flyash Composite. Adv. Chem. Eng. Sci. 2011, 1, 37-44. 